\title{
MEMBERS OF THE COUNCIL
}

\section{9}

OfFICRRS.

Maxime Bôcher, President.

$\left.\begin{array}{l}\text { EDWARD KaSNer, } \\ \text { E. B. VAN VLECK, }\end{array}\right\}$ Vice-Presidents.

F. N. CoLe, Secretary.

J. H. TANNER, Treasurer.

D. E. Sмrтн, Librarian.

F. N. CoLe,

D. E. Sмiтн, VIRGIL SNYDER,

\section{Ex-Presidents.}

$\begin{array}{lll}\text { J. H. Van Amringe, } & \text { Simon Newcomb, } & \text { T. S. Fiske, } \\ \text { Emory MoChintock, } & \text { R. S. WoodWard, } & \text { W. F. OsGood, } \\ \text { G. W. Hili, } & \text { Eliakim H. MoORe, } & \text { H. S. WHite. }\end{array}$

EleCted Members.

To Serve until December, 1909.
G. A. BLiss,
M. W. HASKELL,
E. W. Brown,
A. G. Webster.

To Serve until December, 1910.

R. E. Altardice, Max Mason, G. D. OLds, M. B. Porter.

To Serve until December, 1911.

H. B. FINE,

O. D. Kelloga, F. R. Moulton, E. J. WILCZYNSKr.

Editorial Committee of the transactions.

Maxime Bôcher, E. B. Van Vleck, H. S. White. 
